\title{
A Virtual Efficient Driving Training Simulator for both Driver and Non-Driver
}

\author{
Seung Yeol Kim and Yoon Sang Kim \\ Department of Computer Science and Engineering, \\ Korea University of Technology and Education, \\ 330-708 Cheonan, Chungnam, South Korea \\ yoonsang@koreatech.ac.kr
}

\begin{abstract}
This paper proposes a virtual eco-driving simulator for providing efficient driving style training for drivers and non-drivers. The proposed system aims at improving fuel efficiency and reducing the wear of consumables based on visual and auditory feedback. For driver and non-driver participants in the experiment, we measured fuel economies and levels of consumable wear according to 3 types of feedback (no feedback, visual feedback, visual and auditory feedback). The experimental results confirm that drivers and non-drivers were able to achieve higher fuel economy and reduce consumable wear when they received feedback from the proposed system compared to driving without feedback.
\end{abstract}

Keywords: Eco-driving, virtual driving simulator, vehicle consumables, fuel efficiency, wear simulation

\section{Introduction}

In order to cope with recent issues such as soaring oil prices and carbon emission reduction efforts, a wide range of energy saving technologies are being applied on vehicles. Among them, eco-driving is an effective means of resolving environmental and cost issues without incurring additional financial burden. In developed countries, various eco-driving programs [1] have been developed and are being actively used in training. Eco-driving training which uses the simulator fundamentally reduce traffic accidents and greenhouse gas emissions. Examples include the Eco-Driving Simulator [2] from Simax.Virt.S.L and the Jetig50 Simulator [3] from ST Software. While these simulators offer effective training by implementing environments similar to the actual driving experience, they have limitations such as high costs and space requirement. This paper proposes a virtual eco-driving training simulator to foster efficient driving habits among drivers and non-drivers based on personal computers (PC) which does not require a large amount of space. The proposed simulator uses the virtual driving experience to create an environment where not only drivers but also nondrivers who have yet to obtain a driver's license can easily follow the eco-driving style. Unlike conventional systems that focus only on improving fuel efficiency and fuel economy, the proposed system provides a training environment which allows the user to develop a driving habit that would help slow down the wear of consumables and help reduce maintenance costs. In order to examine the effects of the proposed virtual eco-driving training simulator, three experiments were conducted and the results are discussed in the following sections. H.264 is a standard for video compression, and it is currently one of the most 
commonly used formats for the recording, compression, and distribution of high definition video.

\section{Proposed Virtual Driving Simulator for Efficient-driving Training}

\subsection{Summary of Application}

The virtual eco-driving training system proposed in this paper is shown in Figure 1. The user maneuvers the steering wheel and the pedals to participate in the driving simulation experience in an environment similar to actual driving. The proposed system provides driving as well as visual and auditory feedback related to eco-driving, allowing the user to acquire environment-friendly driving habits.

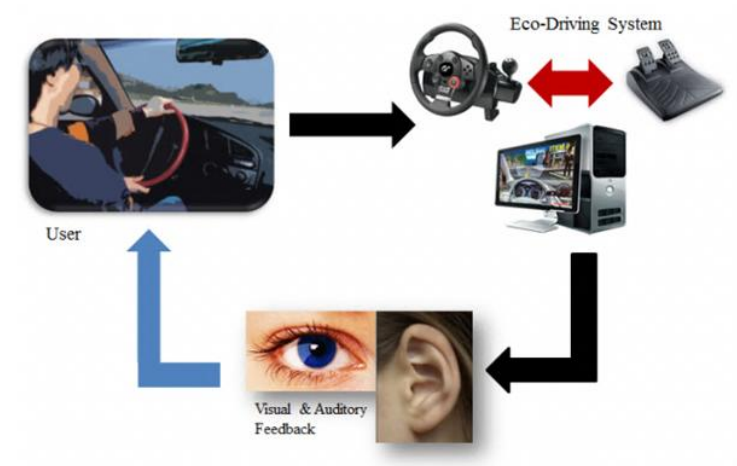

Figure 1. Overview of the proposed virtual eco-driving training simulator

Four types of eco-driving feedback based on [5, 6, 7] are provided for eco-driving, as shown in Table 1.

Table 1. Four types of eco-driving feedback for the proposed eco-driving training system

\begin{tabular}{c|c}
\hline $\begin{array}{c}\text { Types of eco-driving } \\
\text { feedback }\end{array}$ & Description \\
\hline $\begin{array}{c}\text { Maintain efficient } \\
\text { speed }\end{array}$ & $\begin{array}{c}\text { Maintain speeds between } 60 \text { and } 80 \mathrm{~km} / \mathrm{h} ; \\
\text { avoid driving at excessive speeds }\end{array}$ \\
\hline $\begin{array}{c}\text { Avoid sudden } \\
\text { acceleration }\end{array}$ & $\begin{array}{c}\text { Reduce fuel consumption by avoiding excessive } \\
\text { pressing of the accelerator }\end{array}$ \\
\hline Avoid abrupt braking & $\begin{array}{c}\text { Avoid abrupt braking during deceleration to reduce } \\
\text { energy consumption and consumable wear }\end{array}$ \\
\hline $\begin{array}{c}\text { Maintain optimum } \\
\text { gear }\end{array}$ & Maintain high gear to increase fuel efficiency \\
\hline
\end{tabular}

\subsection{Dynamics Simulation for Efficient-driving Training}

Vehicle simulation for proposed eco-driving training consists of three main functions: 1) the longitudinal simulation for calculating vehicle's accelerating and decelerating motions $[8,9,10,11] ; 2)$ fuel consumption simulation for calculating the vehicle's fuel consumption $[12,13]$; and 3 ) wear simulation for calculating the wear of vehicle consumables - tires and brake pads - caused by acceleration and braking [14]. 
Figure 2 shows the block diagram of vehicle simulation using the proposed eco-driving training simulator.

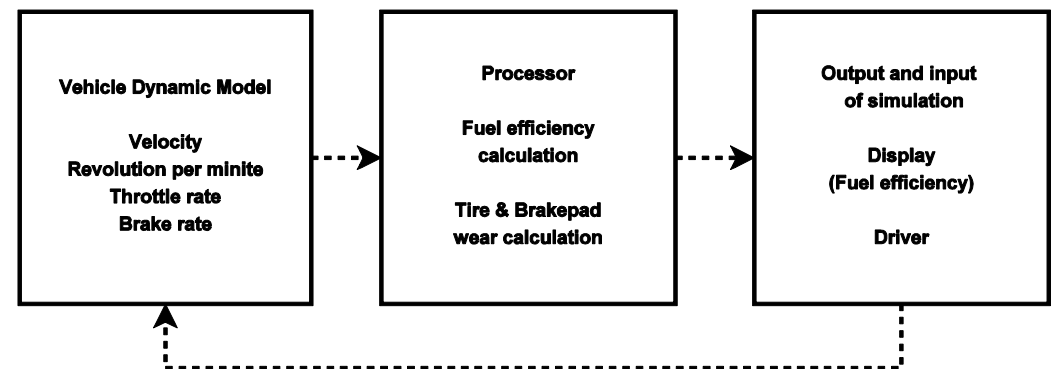

Figure 2. Block diagram of vehicle simulation using the proposed ecodriving training simulator

\subsubsection{Longitudinal Simulation:}

A. Acceleration performance simulation: Increasing power delivered to accelerating wheels eventually poses limits in power and traction. In power limited acceleration, the vehicle reaches its peak acceleration because the engine can no longer deliver additional power.

In traction limited acceleration, the engine can and does deliver more power, but vehicle acceleration is limited because the tires cannot transmit any more driving force to the ground. Equation (1) gives the maximum transmittable force.

$$
F_{X}=\mu F_{Z}
$$

Where

$$
F_{X}=\text { Tractive Force }
$$

Where $\mu$ is the coefficient of friction between the tire and the road. Note that $\mu$ depends on many factors, including load and velocity.

If $F_{X}$ exceeds this limit, the tire slips excessively and enters dynamic friction, where the coefficient of friction dramatically decreases, i.e., it loses traction. The acceleration of the vehicle (and therefore the longitudinal forces on the tires) at a given point can be determined from Equation (2).

$$
\left(M+M_{r}\right) a_{x}=\frac{W}{g} a_{x}=\frac{\tau_{e} N_{t f} n_{t f}}{r}-R_{X}-D_{A}-W \sin \theta
$$

Where

$$
\begin{aligned}
& \mathrm{M}=\text { Mass of the vehicle }=\mathrm{W} / \mathrm{g} \\
& M_{r}=\text { Equivalent mass of the rotating components } \\
& a_{x}=\text { Longitudinal acceleration } \\
& \mathrm{W}=\text { Weight of the vehicle } \\
& R_{X}=\text { Rolling resistance forces } \\
& D_{A}=\text { Aerodynamic drag force } \\
& T_{e}=\text { engine torque at a given rpm (from dynamometer data) }
\end{aligned}
$$




$$
\begin{aligned}
& N_{t f}=\text { combined ratio of the transmission and final drive } \\
& n_{t f}=\text { combined efficiency of the transmission and final drive } \\
& \mathrm{r}=\text { radius of the tire }
\end{aligned}
$$

Engine torque is measured at a steady speed on a dynamometer. Thus, the actual torque delivered to the drivetrain is reduced by the amount of torque required to accelerate the inertia of the rotating components.

B. Braking performance simulation: The general equation for braking performance is written as Equation (3)

$$
\text { . (M) } a_{X}=-\frac{(W)}{g} D_{X}=-F_{X f}-F_{X r}-R_{X}-D_{A}-W \sin \theta
$$

Where

$$
\begin{aligned}
& \mathrm{M}=\text { Mass of the vehicle }=W / g \\
& D_{X}=\text { Linear deceleration } \\
& F_{X f}=\text { Front axle braking force } \\
& F_{X r}=\text { Rear axle braking force } \\
& R_{X}=\text { Rolling resistance forces } \\
& D_{A}=\text { Aerodynamic drag force } \\
& \Theta=\text { Uphill grade }
\end{aligned}
$$

As with acceleration, braking is usually limited by friction. The torque produced by the brake generates a braking force at the ground to decelerate the wheels and the driveline components [Equation (4)].

$$
F_{b}=\frac{\left(T_{b}-l_{W} a_{W}\right)}{r}
$$

Where

$$
\begin{aligned}
& T_{b}=\text { Brake torque } \\
& \mathrm{r}=\text { Rolling radius of the tires } \\
& l_{W}=\text { Rotational inertia of the wheels and driveline components } \\
& a_{W}=\text { Rotational deceleration of the wheels }
\end{aligned}
$$

C. Environmental forces simulation: Braking and acceleration forces are applied by the vehicle, and there are two primary environmental forces operating on a vehicleaerodynamic load and tire friction (rolling resistance). The aerodynamic load is aerodynamic drag, which is given by Equation (5).

$$
F_{d}=0.5 \rho C_{d} A V^{2}
$$

Where

$$
\begin{aligned}
& \rho=\text { air density } \\
& C_{d}=\text { drag coefficient } \\
& \mathrm{A}=\text { frontal area of the vehicle } \\
& \mathrm{V}=\text { velocity }
\end{aligned}
$$


$C_{d}$ is usually determined from wind tunnel tests. (There are other methods of estimating the drag coefficient from coast-down tests.) Rolling resistance is caused by the tire's resistance to deformation, scrubbing losses in the contact patch, tire slip, and air drag on the tire, among other things. Unlike aerodynamic forces, rolling resistance becomes effective as soon as the tire starts rotating. Aerodynamic loads only become equal to rolling resistance at 50-60 mph for modern passenger cars. The basic equation for rolling resistance is Equation (6).

$$
R_{X}=f_{r} W
$$

Where

$$
f_{r}=\text { rolling resistance coefficient }
$$

2.2.2. Fuel consumption simulation: Fuel consumption simulation is performed by calculating the amount of fuel consumed by the vehicle. Injection quantity is determined by how much acceleration pedal is pressed by the driver, and injection timing is determined by the piston speed of the engine, which can be determined in association with the engine's RPM. Once fuel consumption is calculated, fuel economy can be obtained by dividing the amount of fuel consumption by the distance traveled. Therefore, to calculate fuel economy, the most important elements are engine's RPM and throttle condition. Fuel economy is determined by Equation $(7)[12,13]$.

$$
F_{e}=\frac{D_{t}}{C_{\epsilon}\left(E_{r} A_{v}\right)}
$$

Where

$$
\begin{aligned}
& F_{e}=\text { Fuel economy } \\
& C_{\epsilon}=\text { Constant of fuel consumption } \\
& E_{r}=\text { Rpm of engine } \\
& A_{v}=\text { Position of throttle }
\end{aligned}
$$

2.2.3. Vehicle consumption simulation: Vehicle consumable wear simulations are performed by calculating the wear of tire and the brake pad during abrupt acceleration and deceleration. In addition to increasing fuel economy, driving habits to reduce consumable wear allow the life of consumables, significantly helping to reduce vehicle maintenance costs. In this simulation, wear levels of vehicle tire and brake pad are analyzed for various driving conditions, and the results are displayed to the user. Based on the wear simulation, the proposed system helps to prolong the life of consumables to not only protect the environment but also reduce costs required for vehicle maintenance.

A. Tire wear simulation: Sudden acceleration and sudden braking are determined if throttle open valve and brake open valve are above specific levels, respectively. Figure 3 shows the flowchart for tire wear simulation and Table 2 shows the tire wear conditions used in the simulation [14]. 


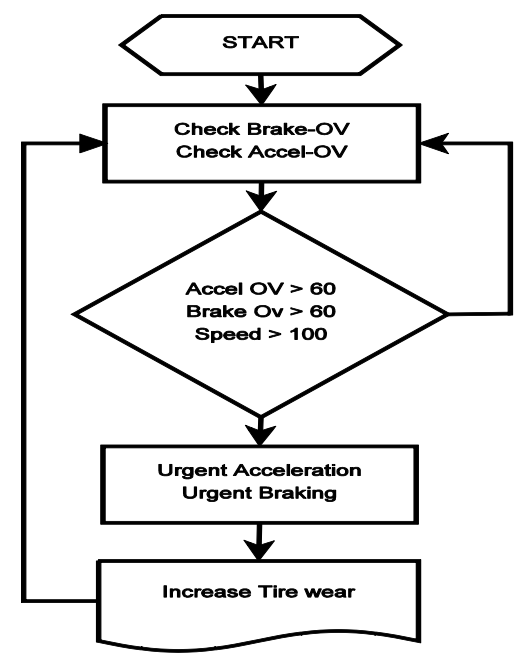

Figure 3. Flowchart for tire wear simulation

Table 2. Tire wear condition used in the simulation

\begin{tabular}{c|c}
\hline Condition & Description \\
\hline Quick braking & Tire wear by wheel lock \\
\hline Quick Acceleration & Tire wear by wheel spin \\
\hline High Speed & Severe tire wear at high speed \\
\hline
\end{tabular}

B. Brake pad wear simulation: Brake pad wear simulation is performed when brake valve opening exceeds a specific level and abrupt deceleration is determined, as shown in Figure 4. In this simulation, brake pad is only affected by brake control, and no other conditions are taken into account. Table 3 shows the brake pad wear conditions used in the simulation [15].

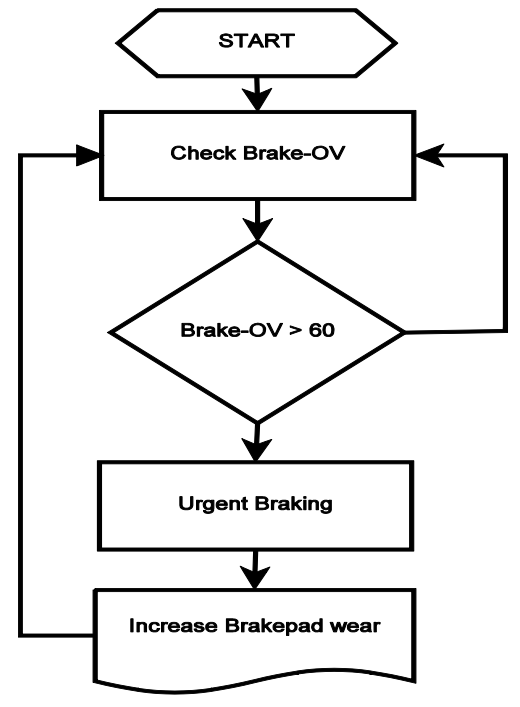

Figure 4. Flowchart for brake pad wear simulation 
Table 3. Brake pad wear conditions used in the simulation

\begin{tabular}{c|c}
\hline Condition & Explanation \\
\hline Quick braking & Increased wear of brake pads due to increased friction \\
\hline Steady Braking & Increased loss due to unnecessary use of the brake \\
\hline
\end{tabular}

\section{Experimental}

This section explains the experiments conducted to examine the benefits of eco-driving training (improving fuel economy and reduction of consumable wear) provided by the proposed virtual simulator. The experimental subjects were divided into drivers and nondrivers, and experiments were conducted while the subjects were engaged in virtual driving with and without eco-driving feedback.

\subsection{Experimental environment}

A total of 12 subjects (10 male, 2 female) aged between 23 and 28 were divided into two groups of 6 (driver Group A and non-driver Group B). As shown in Figure 5, the experiments were conducted in the virtual driving environment, which consisted of $1.5 \mathrm{~km}$ of urban streets [Figure 5(a)] and $3.6 \mathrm{~km}$ of a national highway [Figure 5(b)]. The destination was fixed at a specific location [Figure 5(c)], and the direction from the current location to the destination was displayed on the vehicle HUD so that the subject could intuitively understand where the vehicle was headed [Figure 5(d)]. We implemented a low-cost system design for high accessibility [Figure 5(e)].

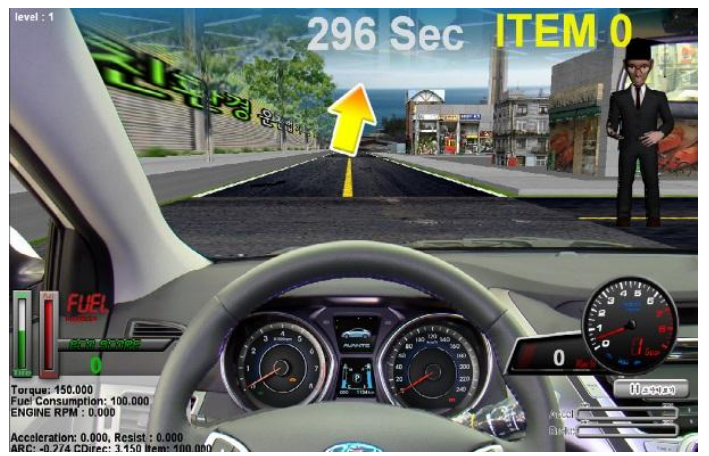

(a) Urban street driving

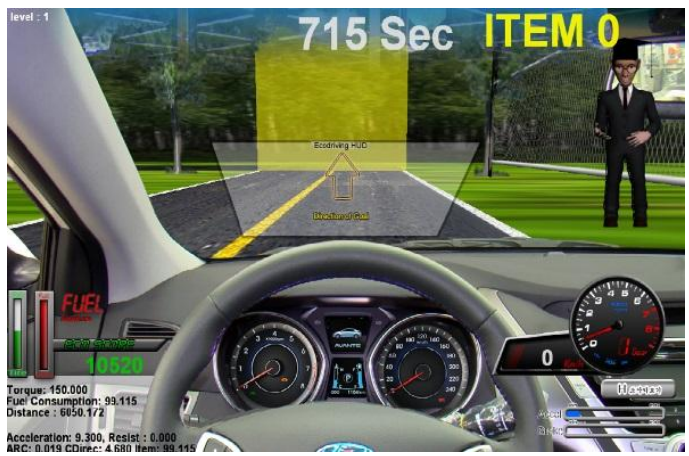

(c) Destination

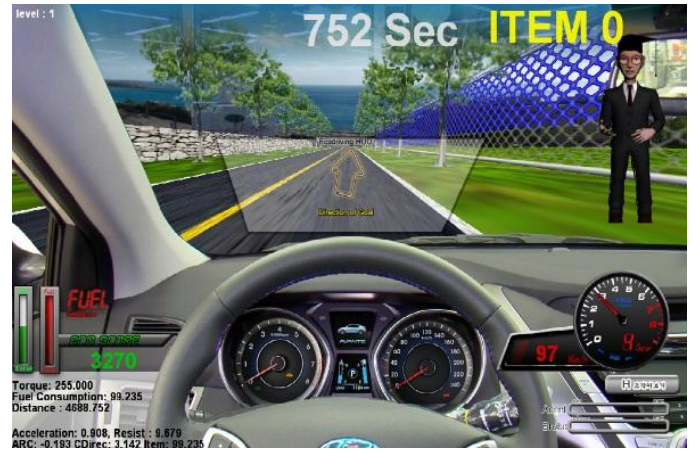

(b) National highway driving

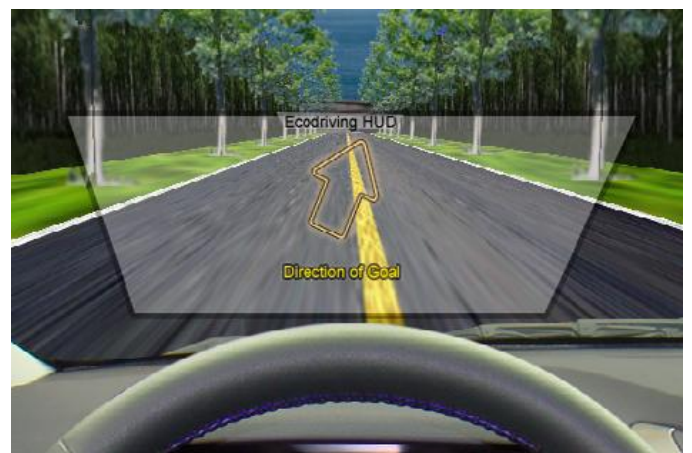

(d) Destination guidance by HUD 


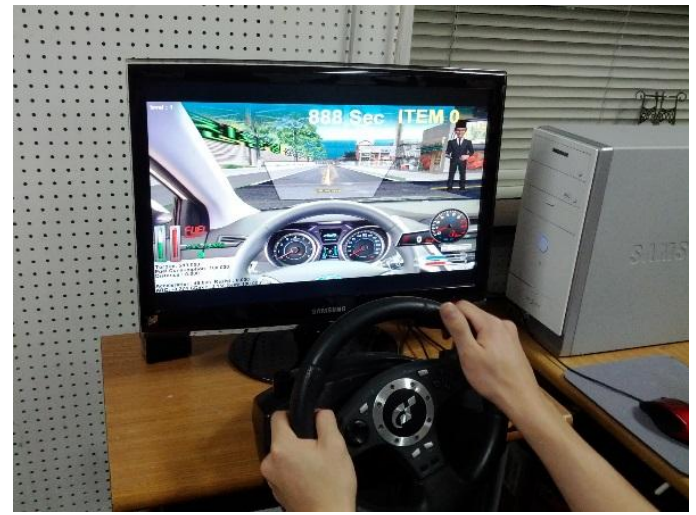

(e) Experimental environment using the eco-driving training simulator

\section{Figure 5. Experimental environment of the proposed eco-driving system.}

After allowing subjects sufficient practice driving sessions to become accustomed to virtual driving, the experiments were conducted in the following order: 1) drive with normal driving habits and calculate the fuel economy (Experiment 1);2) drive while receiving visual eco-driving feedback and calculate the fuel economy (Experiment 2); 3) drive while receiving visual and auditory feedback and calculate the fuel economy (Experiment 3). The fuel economies on the three virtual driving tests were obtained and recorded. In order to increase the reliability of the experiments, we prevented the "sequential effect" and the "practice effect" from repeated experiments by employing the "cross-equalization" process [16], which involved assigning experimental conditions in a random order for each subject to offset the sequential effects so that they would not affect the outcome.

\subsection{Experimental results and discussion}

Once each subject completes the virtual driving, the driving distance, fuel economy, fuel consumption, and consumable (tire and brake pad) wear levels (low, medium, or high) are obtained as shown in Figure 6. The fuel economy, which incorporates the driving distance and fuel consumption, and consumable wear levels determine the benefits of eco-driving high fuel economy and low consumable wear levels indicate significant effects of eco-driving training. The test results of the two groups (drivers and non-drivers) are shown in Figure 7.

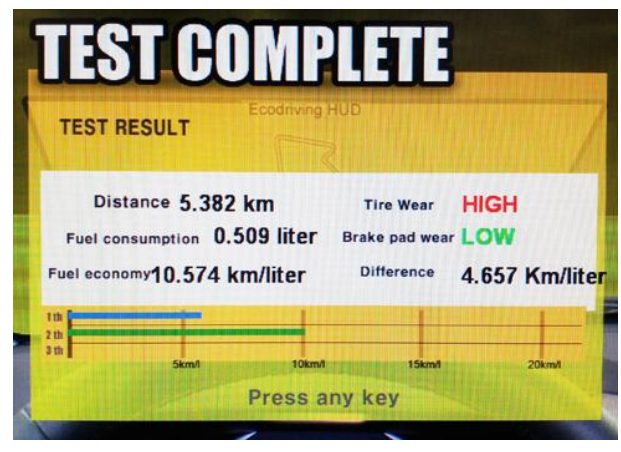

Figure 6. An example of experimental results 


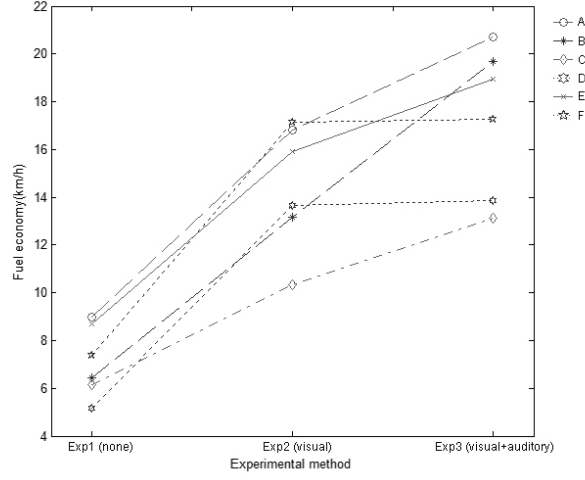

(a)

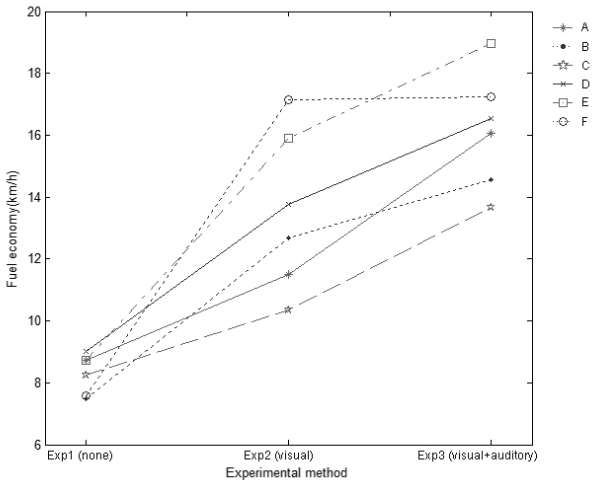

(b)

Figure 7. Experimental results obtained by (a) Group A and (b) Group B

Since we designed a repetitious measurement experiment around a single factor by varying the types of feedback, the results were analyzed using one-way analysis of variance (ANOVA) [17]. The experimental results are shown in Table 7. In Group A (drivers), compared to Experiment 1, fuel economy improved in Experiments 2 and 3 by $103.45 \%$ and $141.96 \%$, respectively $(7.13 \mathrm{~km} / \mathrm{l}$ in Experiment $1,14.51 \mathrm{~km} / 1$ in Experiment 2, and 17.26 $\mathrm{km} / \mathrm{l}$ in Experiment 3). In Group B (non-drivers), compared to Experiment 1, fuel economy improved by $57.18 \%$ in Experiment 2 where visual feedback was provided, and by $99 \%$ in Experiment 3 where visual and auditory feedback was provided $(7.88 \mathrm{~km} / 1$ in Experiment 1 , $12.38 \mathrm{~km} / \mathrm{l}$ in Experiment 2, and $15.67 \mathrm{~km} / 1$ in Experiment 3). Accordingly, we were able to confirm that eco-driving using the proposed system effectively improves fuel economy. Furthermore, results of Experiment 3 indicate that eco-driving training with visual and auditory feedback is most effective.

Table 4. Improvement in fuel economy from three experiments

\begin{tabular}{c|c|c|c|c}
\hline Experiment & $\begin{array}{c}\text { Subject } \\
\text { Group }\end{array}$ & Average & $\begin{array}{c}\text { Standard } \\
\text { Deviation }\end{array}$ & Improvement \\
\hline \multirow{2}{*}{ Experiment 1 } & Group A & 7.1343 & 1.50535 & 0 \\
\cline { 2 - 5 } & Group B & 7.8762 & 0.96610 & 0 \\
\hline \multirow{2}{*}{ Experiment 2 } & Group A & 14.5145 & 2.60783 & $103.45 \%$ \\
\cline { 2 - 5 } & Group B & 12.3797 & 1.53816 & $57.18 \%$ \\
\hline \multirow{2}{*}{ Experiment 3 } & Group A & 17.2620 & 3.13386 & $141.96 \%$ \\
\cline { 2 - 5 } & Group B & 15.6737 & 1.29671 & $99 \%$ \\
\hline
\end{tabular}

From the results of the experiments conducted with drivers (Group A) and non-drivers (Group B), we examined from Table 5 whether the proposed system could be used in training non-drivers prior to obtaining driver's license. The interaction effect in Table 5 is $\mathrm{F}=1.760$, $\mathrm{p}$-value $=.189$, which means that the hypothesis "there is no interaction effect with driving experience" cannot be rejected. Therefore, the experimental results suggest that there is no interaction effect between the type of feedback and driving experience. Figure 8 displays two parallel lines, which demonstrates absence of interaction effect. In terms of the main effect of driving experience, $\mathrm{F}=2.234$ and $\mathrm{p}$-value $=0.145$, indicating that there is no difference in fuel 
economy based on driving experience. In other words, a non-driver is just as likely as a driver to achieve improvement in fuel economy from the system feedback. Therefore, we can conclude that the proposed eco-driving training simulator is effective for training non-drivers prior to obtaining driver's license.

Table 5. Verification of effects according to possession of driver's license and type of feedback

\begin{tabular}{c|c|c|c|c|c|c}
\hline Source & $\begin{array}{c}\text { Type III } \\
\text { Sum of Squares }\end{array}$ & $\begin{array}{c}\text { Degree of } \\
\text { Freedom }\end{array}$ & $\begin{array}{c}\text { Mean } \\
\text { Square }\end{array}$ & F & $\begin{array}{c}\text { Significance } \\
\text { Probability }\end{array}$ & $\begin{array}{c}\text { Partial Eta } \\
\text { Squared }\end{array}$ \\
\hline $\begin{array}{c}\text { Correction } \\
\text { Model }\end{array}$ & $515.925^{\mathrm{a}}$ & 5 & 104.385 & 26.240 & .000 & .814 \\
\hline Intercept & 5607.075 & 1 & 5607.075 & 1407.974 & .000 & .979 \\
\hline $\begin{array}{c}\text { Type of } \\
\text { feedback }\end{array}$ & 499.033 & 2 & 249.516 & 62.722 & .000 & .807 \\
\hline $\begin{array}{c}\text { Possession of } \\
\text { driver's license }\end{array}$ & 8.888 & 1 & 8.888 & 2.234 & .145 & .069 \\
\hline $\begin{array}{c}\text { Type of } \\
\text { Feedback } \\
\text { *Driving } \\
\text { Experience }\end{array}$ & 14.004 & 2 & 7.002 & 1.760 & .189 & .105 \\
\hline Error & 119.343 & 30 & 3.978 & & & \\
\hline Total & 6242.344 & 36 & & & & \\
\hline $\begin{array}{c}\text { Correction } \\
\text { Total }\end{array}$ & 641.268 & 35 & & & & \\
\hline
\end{tabular}

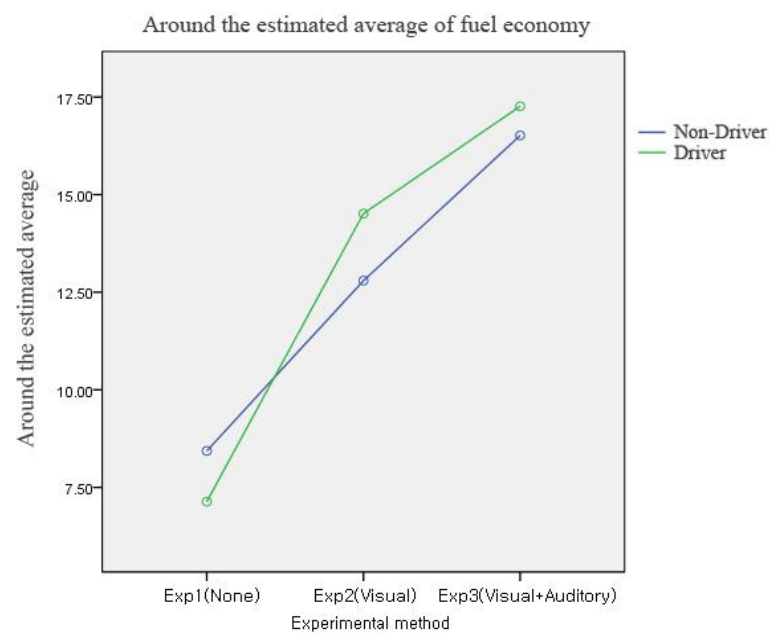

Figure 8. Fuel economy profile graph according to possession of driver's license

As with the fuel economy experiment, vehicle consumable wear simulation performed with three experiments confirmed that the subjects were able to reduce consumable wear when 
they received visual feedback compared to driving without any feedback. They were able to further lower wear levels when visual and auditory feedback was provided. Figure 9 displays the results of vehicle consumable wear simulation performed based on the tree experiments.

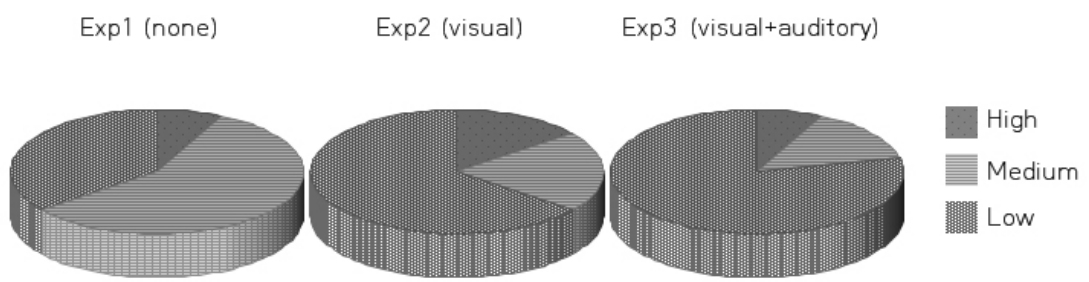

Figure 9. Levels of vehicle consumable wear

\section{Conclusions}

This paper proposed a virtual eco-driving simulator for training drivers and non-drivers regarding efficient driving habits. The proposed virtual eco-driving training simulator offers an environment where not only drivers but also non-drivers who have yet to obtain driver's license can easily acquire the eco-driving style. Unlike conventional systems that only focus on improving fuel efficiency and fuel economy, the proposed system provides a training environment that allows the user to develop a driving habit for slowing the wear of consumables, helping to reduce maintenance costs. In order to examine the effects of the proposed system and method, we divided the subjects into two groups and conducted three experiments. Based on the experimental results, we were able to confirm that providing visual and auditory feedback simultaneously maximizes the benefits of eco-driving training. Moreover, the results obtained from non-drivers were similar to those produced by drivers, indicating that the proposed system and method could be applied for non-drivers training. The approach proposed in this paper is expected to help non-drivers develop good driving habits at the initial stage of learning to drive, and alleviate problems such as environmental issues and high gasoline prices until pollution-free vehicles replace conventional automobiles.

\section{Acknowledgments}

This paper was supported by the 2012 Sabbatical Year Research Program of KoreaTech.

\section{References}

[1] O. Jung, "Review of Eco-Driving Policy in Advanced Countries and Its Implication", The Korea Transport Institute, KOTI Research, Seoul, (2009).

[2] Simax. Virt.S.L Eco-Driving Simulator, http://www.simaxvirt.com.

[3] ST software The Jentig50 Simulator, http://www.stsoftware.nl.

[4] PSW Leisure ECO Driving Simulator, http://www.psw-leisure.co.uk.

[5] Korea Automobile Association Eco-Driving, http://www.eco-drive.or.kr.

[6] Cambridge Driving School Eco-Driving tips http://www.cambridgedrivingschool.net.

[7] Europe ECOWILL project, http://www.ecodrive.org/en/home/ecowill_the_project.

[8] T. Zuvich, "Vehicle Dynamics for Racing Games", http://transpoter-game.googlecode.com.

[9] B. Beckman, "The Physics of Racing", The Magic Formula, (1991).

[10] T. D. Gillespie, "Fundamentals of Vehicle Dynamics", Society of Automotive Engineers, Inc. Warrendale, (1992).

[11] D. C. Lee, N.Baek, W. Lee and K. W.Ryu, "The simplified simulation model for real-time vehicle motion", in Proceedings of The KIISE conference, Seoul, Korea, vol. 27, no. 2, (2000), pp. 517-519. 
[12] J. Park, J. Kong, H. Jo, Y. Park and J. Lee, "A Study on the prediction of the real driving fuel consumption rate of a vehicle", Proceedings The KSAE conference, Daegu, Korea, no. 2, (1999), pp. 755-762.

[13] M. -S. Kim and K. -H. Kim, "Prediction of Vehicle Acceleration Performance and Fuel Economy", the Korean Society of Mechanical Engineers, vol. 33, no. 10, (1993), pp. 861-870.

[14] J. -H. Choi, J. -R. Cho, G. -J. Kim and J. -S. Woo, "Study of Tire wear Amount Prediction Utilizing the Tire Dynamic Rolling Analysis", Proceedings The KSME conference, Pyeongchang, Korea, (2005), pp. 19631968.

[15] T. Yeo, "Study on Wear Life Prediction of Disk Brake Pads", KSME, The Transaction of the Korean Society of Automotive Engineers, vol. 10, no. 4, (2002), pp. 199-205.

[16] I. -H., Lee and J. -H. Im, "Statistical Package for the Social Sciences 18.0. Manual and J.H. Jae", Seoul, Korea, (2011).

[17] Y. -O. Kim and Y. S. Kim, "Utilizing a Haptic Display in Multimedia Education", The Transaction of the Korean Institute of Electrical Engineers, vol. 57, no. 7, (2006), pp.78-80.

\section{Authors}

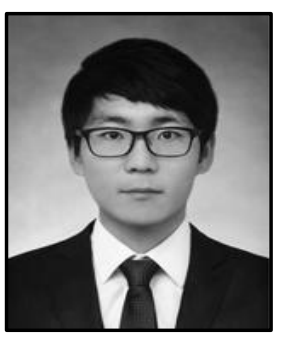

\section{Seung Yeol Kim}

He obtained the B.S and M.S degrees in Department of Computer Science and Engineering from Korea University of Technology and Education, Cheonan, Korea, in 2011 and 2013 respectively. His current research interests include smart vehicle and Image and video processing.

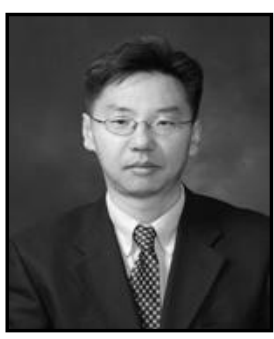

\section{Yoon Sang Kim}

He received the B.S., M.S., and Ph.D. degrees in Electrical Engineering from Sungkyunkwan University, Seoul, Korea, in 1993, 1995, and 1999, respectively. From 1999 to 2000 he was a member of the Postdoctoral Research Staff of Korea Institute of Science and Technology (KIST), Seoul, Korea. From 2000 to 2003 he was a Faculty Research Associate in the Department of Electrical Engineering, University of Washington, Seattle. From 2003 to 2005 he was a Member of the Senior Research Staff, Samsung Advanced Institute of Technology (SAIT), Suwon, Korea. Since 2005, he has been an Associate Professor at the School of Computer Science and Engineering, Korea University of Technology Education (KOREATECH), Cheonan, Korea. His current research interests include Virtual simulation, Power-IT technology, and Bio-informatics. Dr. Kim was awarded the Korea Science and Engineering Foundation (KOSEF) Overseas Postdoctoral Fellow in 2000. $\mathrm{He}$ is a member of IEEE, IEICE, ICASE, KIPS, and KIEE. 